\title{
The efficacy and safety of pre-hospital cooling after out-of-hospital cardiac arrest: a systematic review and meta-analysis
}

\author{
Patrick J. Lindsay ${ }^{1 *+} \mathbb{B}$, Danielle Buell ${ }^{1+}$ and Damon C. Scales ${ }^{1,2,3}$
}

\begin{abstract}
Background: Mild therapeutic hypothermia $(T H)$, or targeted temperature management, improves survival and neurological outcomes in patients after out-of-hospital cardiac arrest (OHCA). International guidelines strongly support initiating TH for all eligible individuals presenting with OHCA; however, the timing of cooling initiation remains uncertain. This systematic review and meta-analysis was conducted with all available randomised controlled trials (RCTs) included to explore the efficacy and safety of initiating pre-hospital TH in patients with OHCA.

Methods: The MEDLINE and Cochrane databases were searched from inception to October 2017. Inclusion criteria for full-text review included RCTs comparing pre-hospital TH with no pre-hospital TH after cardiac arrest, patients > 14 years of age with documented cardiac arrest from any rhythm, and outcome data that included survival to hospital discharge and temperature at hospital arrival. Results of retrieved studies were compared through meta-analysis using random effects modelling.
\end{abstract}

Results: A total of 10 trials comprising 4220 patients were included. There were no significant differences between the two arms for the primary outcome of neurological recovery (risk ratio [RR] 1.04, 95\% Cl 0.93-1.15) or the secondary outcome of survival to hospital discharge (RR 1.01,95\% Cl 0.92-1.11). However, there was a significantly lower temperature at hospital arrival in patients receiving pre-hospital TH (mean difference $-0.83,95 \% \mathrm{Cl}-1.03$ to -0.63 ). Pre-hospital TH significantly increased the risk of re-arrest (RR 1.19, 95\% Cl 1.00 to 1.41). No survival differences were observed among subgroups of patients who received intra-arrest TH vs post-arrest TH or who had shockable vs nonshockable rhythms.

Conclusions: Pre-hospital TH after OHCA effectively decreases body temperature at the time of hospital arrival. However, it does not improve rates of survival with good neurological outcome or overall survival and is associated with increased rates of re-arrest.

Keywords: Therapeutic hypothermia, Out-of-hospital cardiac arrest, Pre-hospital, Cooling

\section{Background}

Targeted temperature management (TTM) or mild therapeutic hypothermia (TH) has been shown to improve survival and neurological outcomes in patients after out-of-hospital cardiac arrest (OHCA) [1]. Compared with no treatment, cooling the body to 32-34 ${ }^{\circ} \mathrm{C}$ leads to an estimated $35 \%$ relative increase in survival [2]. More recent research suggests that cooling to $36{ }^{\circ} \mathrm{C}$

\footnotetext{
* Correspondence: patrick.lindsay@mail.utoronto.ca

${ }^{\dagger}$ Equal contributors

'Department of Internal Medicine, University of Toronto, Toronto, ON, Canada

Full list of author information is available at the end of the article
}

results in benefits similar to cooling to $32-34{ }^{\circ} \mathrm{C}[3]$. International guidelines strongly support initiating $\mathrm{TH}$ for all eligible individuals presenting with OHCA, but they acknowledge that the optimal target temperature and timing of cooling initiation remain uncertain $[4,5]$. Notably, observational studies and secondary outcomes suggest improved neurological outcomes and survival with earlier and more rapid initiation of cooling, such as initiating cooling prior to hospital arrival [6-8].

Multiple randomised controlled trial (RCTs) have investigated the safety and efficacy of pre-hospital TH; however, all have failed to provide strong evidence to 
support its widespread adoption. The lack of persuasive data could be attributed to underpowered studies, heterogeneity in protocols (e.g., cooling methods, intraarrest vs post-arrest) and the widespread implementation of TH at accepting institutions. Previous meta-analyses have also failed to provide strong data to support recommendations, but these did not include the most recent large trials of pre-hospital cooling [9-12]. We therefore conducted a systematic review and meta-analysis including all available RCTs to explore the efficacy and safety of pre-hospital $\mathrm{TH}$ in patients with OHCA.

\section{Methods}

This systematic review and meta-analysis conformed to the Preferred Reporting Items for Systematic Reviews and Meta-Analyses (PRISMA) statement [13].

\section{Data search}

The online search strategy used both the MEDLINE and Cochrane Library databases from inception until October 2017. The following terms were used: "out-of-hospital cardiac arrest" or "heart arrest" or "cardiac arrest" or "death, sudden" or "ventricular fibrillation" or "pulseless electrical activity" or "PEA" or "asystole" or "tachycardia" and "cryotherapy" or "hypothermia, induced" or "hypothermia" or "cooling" or "targeted temperature management or TTM" and "emergency medical services" or "emergency responders" or "emergency medical technicians" or "paramedic" or "prehospital" or "advanced life support" or "out of hospital." Additionally, we checked reference lists of relevant studies and review articles.

\section{Study selection}

Retrieved abstracts were assessed by two reviewers (PJL and $\mathrm{DB}$ ) to evaluate whether they met the following inclusion criteria for full-text review: (1) RCT evaluating pre-hospital $\mathrm{TH}$ vs no pre-hospital $\mathrm{TH}$ after cardiac arrest; (2) patients > 14 years of age; (3) patients with documented cardiac arrest from rhythms, including ventricular fibrillation (VF), ventricular tachycardia, pulseless electrical activity and asystole; and (4) outcome data that included survival to hospital discharge and temperature at hospital arrival. The same two reviewers completed full-text reviews to identify included studies. A third reviewer resolved any disagreements.

\section{Data extraction}

Two authors (DB and PJL) extracted the following data independently using a standard data extraction form: publication year, study design, study population characteristics, initial cardiac rhythm, timing of cooling, cooling procedures, primary and secondary outcome measures, and study quality.

\section{Risk-of-bias assessment}

Study quality was appraised using the Cochrane Risk of Bias Tool for RCTs [13]. The assessment includes evaluation of random sequence generation, allocation concealment, blinding, incomplete outcome data and selective outcome reporting.

\section{Study outcome definition}

The primary outcome of this systematic review was survival to hospital discharge with a favourable neurological outcome. Favourable neurological outcome was defined as a the patient discharged to home or to rehabilitation, Cerebral Performance Categories Scale (CPC) score of 1 or 2 or a modified Rankin Scale score of 0,1 or $2[14,15]$. Secondary outcomes were survival to hospital discharge and temperature upon hospital admission. The safety outcomes included pulmonary oedema and recurrent arrest during transport to the hospital.

\section{Data synthesis and analysis}

We conducted a meta-analysis of results of the included studies using Review Manager software version 5.3. We summarized categorical data using the risk ratio (RR) according to the Mantel-Haenszel method and a random effects model [16]. For continuous data, we estimated the mean difference (MD) using the inverse variance method and fixed effects. Heterogeneity was detected with a chi-square test with $n-1$ degrees of freedom, which was expressed as $I^{2}$. When the $I^{2}$ statistic was > 50 , statistical heterogeneity was considered to be relevant. Sensitivity analysis were performed to further explore heterogeneity by excluding one study at a time, deleting studies with excessively high weights in pooled studies, and excluding studies that used discharge destination as a surrogate for neurological outcome.

\section{Results}

Search results and study selection

Our search strategy yielded 798 citations in MEDLINE and 84 citations in the Cochrane database, from which 121 duplicates were removed, leaving 761 studies to be screened. Of these, 21 full texts were reviewed, with 10 meeting the study inclusion criteria. All ten were included in the systematic review (Fig. 1).

\section{Characteristics of studies}

Table 1 demonstrates the characteristics of the ten included studies, all of which were RCTs published between 2007 and 2017. Nine were single-country trials, and one was a multi-country trial. Of the single-country trials, four were conducted in Australia [6, 11, 17, 18], two in the United States [19, 20], one in Canada [12], one in Finland [21] and one in France [22]. The multi- 


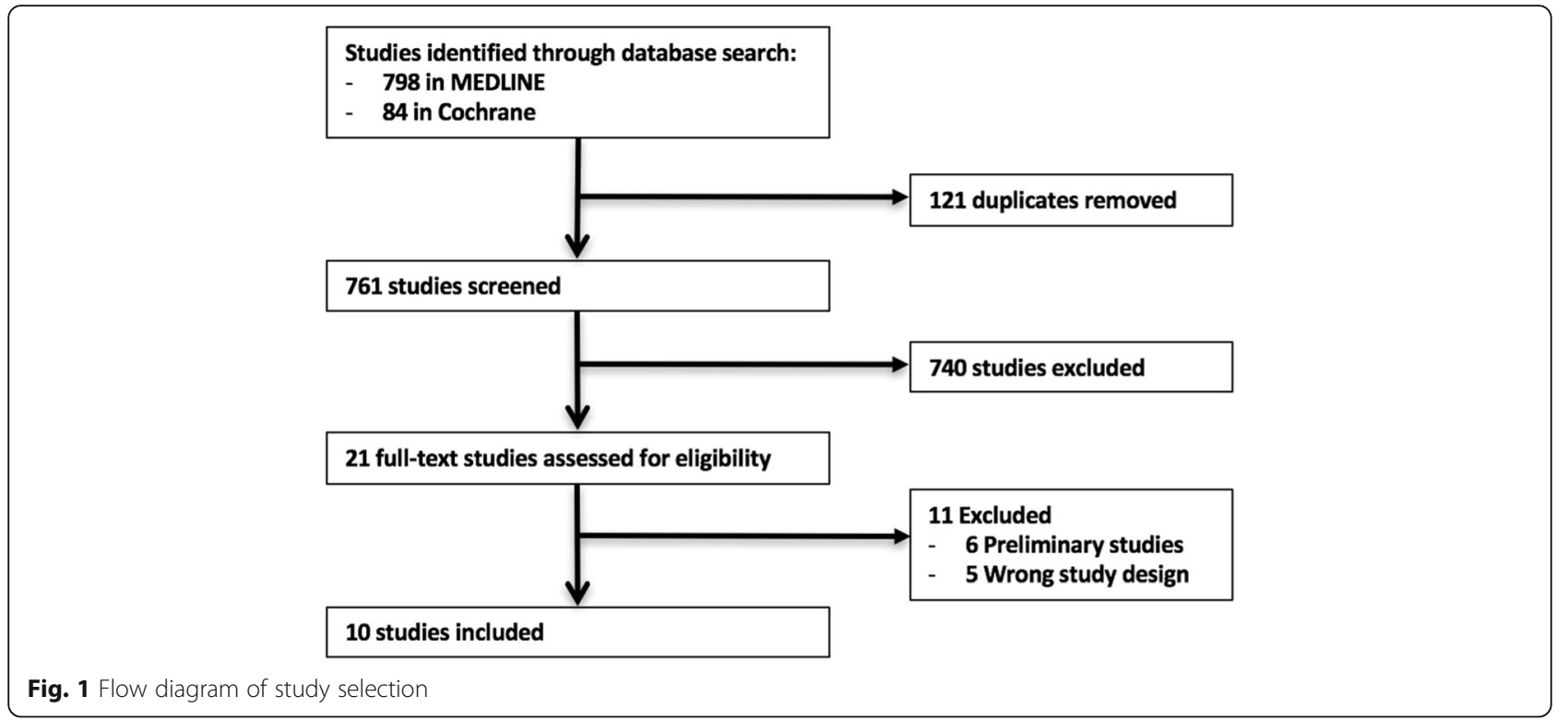

country trial included five European countries [23]. Seven of the ten studies included patients with any initial cardiac rhythm. The remaining three studies included only patients with VF $[6,17]$ and non-shockable rhythms [18], respectively, as the initial cardiac rhythm. TH was initiated after return of spontaneous circulation (ROSC) in seven studies $[6,12,17-21]$ and intra-arrest in three $[11,22,23]$. The majority of studies reported cooling the patients in the pre-hospital $\mathrm{TH}$ arm using surface cooling measures $[12,17-19,22]$, an infusion of a cold solution, normal saline or Ringer's lactate [11, 12, 17-22], and one used trans-nasal evaporative cooling [23]. One study used only ice packs applied to the patient's head and torso [6]. All studies reported survival at hospital discharge and neurological status at discharge, and all studies reported temperature at time of admission to hospital. A summary of the results of the studies is provided in Table 2.

\section{Quality of included studies}

Overall, the risk of bias for the included studies was low (Additional file 1: Figures S1 and S2). A potential for selection bias was noted in one study owing to randomization according to day of the month and possible unmasking of allocation concealment [6]. Across the studies, the nature of the intervention made true blinding of the providers impossible. Additionally, in one study, leaving the receiving practitioner unblinded was an intended intervention, because the authors postulated that this would reduce the time to in-hospital cooling [12]. Outcome assessors for the primary endpoints were blinded in eight of the ten studies. In all of the studies except two, researchers performed an intention-to-treat analysis [6, 21]. All studies had concerns for other sources of bias: Four studies were terminated before the target sample size was recruited [11, 12, 17, 18]; one study was funded by a company with an invested interest [23]; and two studies had concerns for possible selection bias, with 7, 497 and 23 patients simply missed and not included in the study $[6,19,20]$.

\section{Effects of interventions Neurological function}

All included studies reported neurological outcomes at hospital discharge (2129 cases and 2091 control subjects). No differences were observed in rates of favourable neurological outcome at hospital discharge between the prehospital TH arm and the control arm (RR 1.04, 95\% CI 0.93 to $1.15, I^{2}=0 \%$ ) (Fig. 2). Excluding trials that used discharge destination as a surrogate for neurological outcome produced similar results (RR 1.18, 95\% CI 0.93 to $1.49, I^{2}=0 \%$ ) (Additional file 1: Figure S3).

\section{Survival to hospital discharge}

All ten studies reported rates of survival to hospital discharge (2129 cases and 2091 controls). The pooled survival rate was similar when we compared the prehospital TH arm with the control arm (RR 1.01, 95\% CI 0.92 to $1.11, I^{2}=0$ ) (Fig. 3). Sensitivity analyses using data from trials $(n=7)$ that stratified patients according to initial rhythm (i.e., shockable vs non-shockable) $[6,11,12,17,19,20,23]$ also showed no effect of pre-hospital $\mathrm{TH}$ on survival to hospital discharge (Additional file 1: Figures S4 and S5).

\section{Temperature at admission}

All studies reported temperature upon hospital arrival, and overall there was a significantly lower temperature at time of admission for those in the pre-hospital $\mathrm{TH}$ 


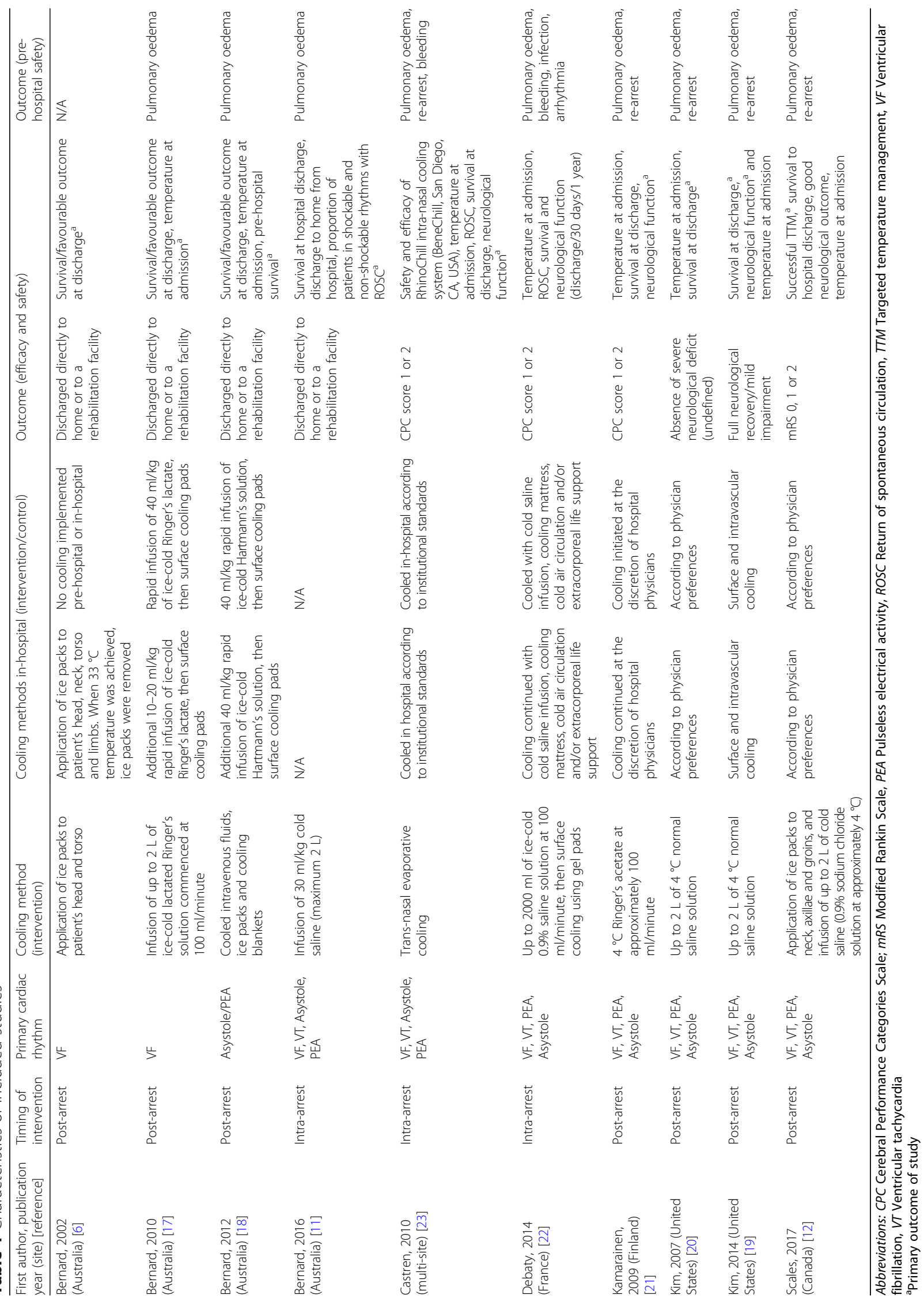




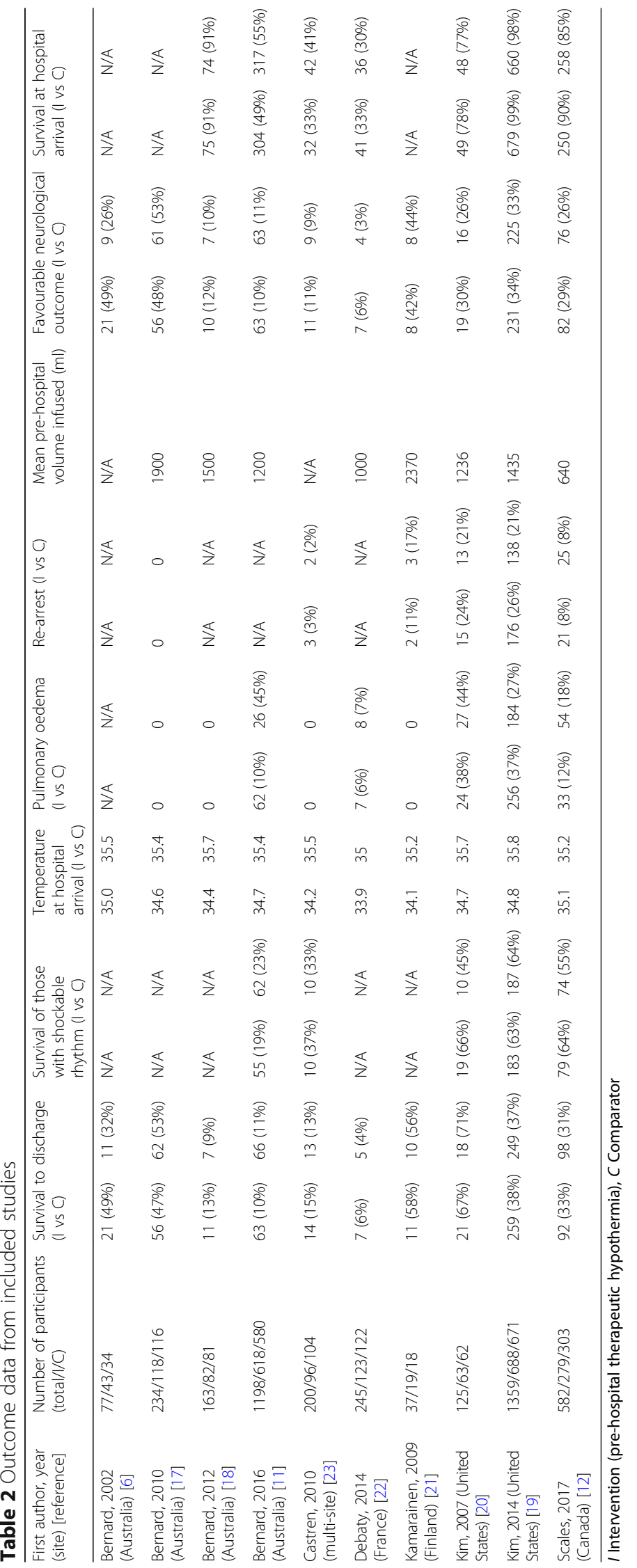




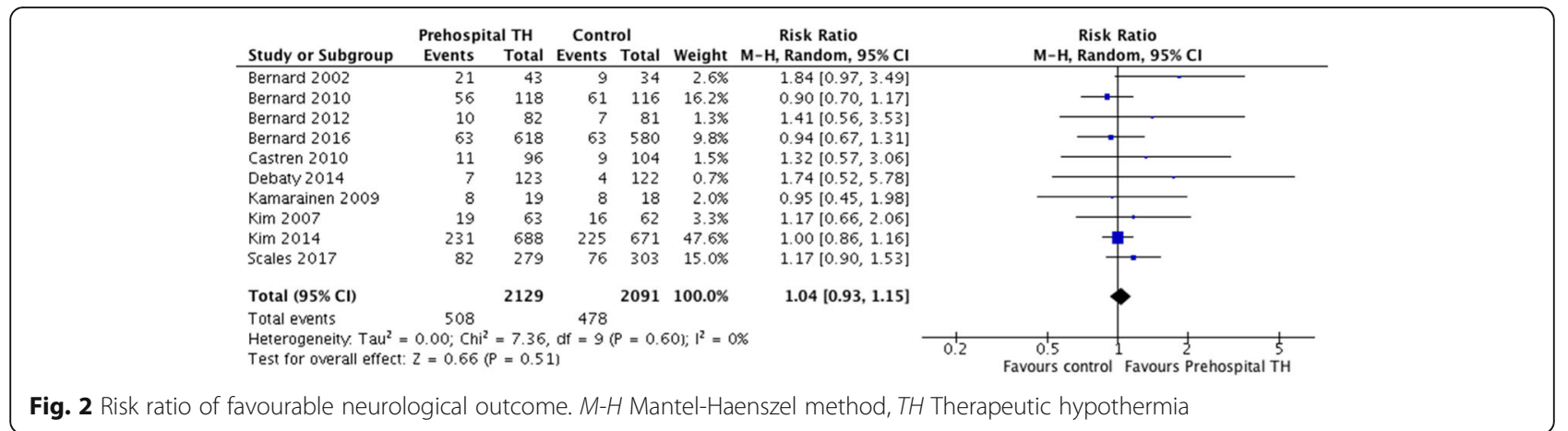

arm than in the control arm $(\mathrm{MD}=-0.83,95 \% \mathrm{CI}-1.03$ to $-0.63, I^{2}=81 \%$ ) (Fig. 4). A sensitivity analysis removing one trial with discordant findings reduced heterogeneity but produced similar results $(\mathrm{MD}=-0.91 ; 95 \% \mathrm{CI}-1.06$ to $-0.76, I^{2}=61 \%$ ) (Additional file 1: Figure S6).

\section{Pre-hospital pulmonary oedema and re-arrest}

Researchers in all studies with the exception of one [6] evaluated their patients for pulmonary oedema. The studies relied on chest $\mathrm{x}$-ray findings or froth visible in endotracheal tubes; however, none of the researchers reported using explicit criteria for pulmonary oedema diagnosis. No differences between groups were observed in the pooled results, but there was significant heterogeneity (RR 1.12 , $95 \%$ CI 0.75 to $1.67, I^{2}=80 \%$ ) (Additional file 1 : Figure S7).

Rates of re-arrest after ROSC ( $n=6$ trials, comprising 1263 cases and 1274 control subjects) were higher among patients treated with pre-hospital TH (RR 1.19, $95 \%$ CI 1.00 to $1.41, I^{2}=0 \%$ ) (Fig. 5). In contrast, there were no significant differences between the two arms in rates of survival to hospital admission (RR $1.00,95 \%$ CI 0.94 to $1.05, n=7$ trials comprising 1949 cases and 1923 control subjects), although greater heterogeneity was observed for this outcome $\left(I^{2}=60 \%\right)$ (Additional file 1: Figure S8) [11, $12,18-20,22,23]$.

\section{Subgroup analyses}

Pre-specified subgroup analyses were performed to evaluate whether initiation of cooling during the arrest ( $n=3$ trials) vs initiation of cooling after $\operatorname{ROSC}(n=7$ trials) led to differences in clinical outcomes, including survival to hospital discharge and rate of re-arrest. No differences in rates of survival to hospital discharge (Additional file 1: Figure S9) or rates of re-arrest (Additional file 1: Figure S10) were observed across these subgroups.

\section{Discussion}

Our systematic review and meta-analysis of pre-hospital cooling after cardiac arrest is the largest to date, to our knowledge, comprising 4220 patients from 10 trials. Our analysis shows that pre-hospital induction of mild $\mathrm{TH}$ reduces the temperature at hospital arrival but does not improve overall survival or survival with good neurological outcome. These results were consistent among patients with shockable and non-shockable initial cardiac rhythms and did not vary according to the timing of cooling initiation (i.e., intra-arrest vs after ROSC).

Previous meta-analyses have evaluated pre-hospital $\mathrm{TH}$ after cardiac arrest, but ours is the first, to our knowledge, to include all available trials, resulting in nearly double the total sample size of previous reviews $[9,10,24-26]$. Despite the improved power and precision of our review, we still detected no benefit of prehospital $\mathrm{TH}$ in our primary outcome of survival with

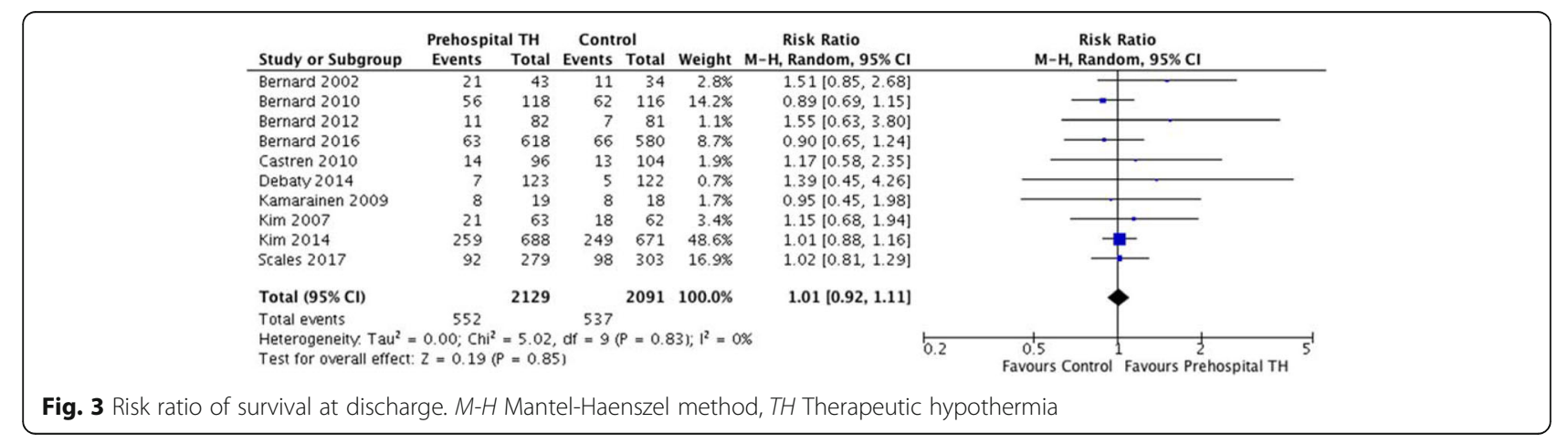




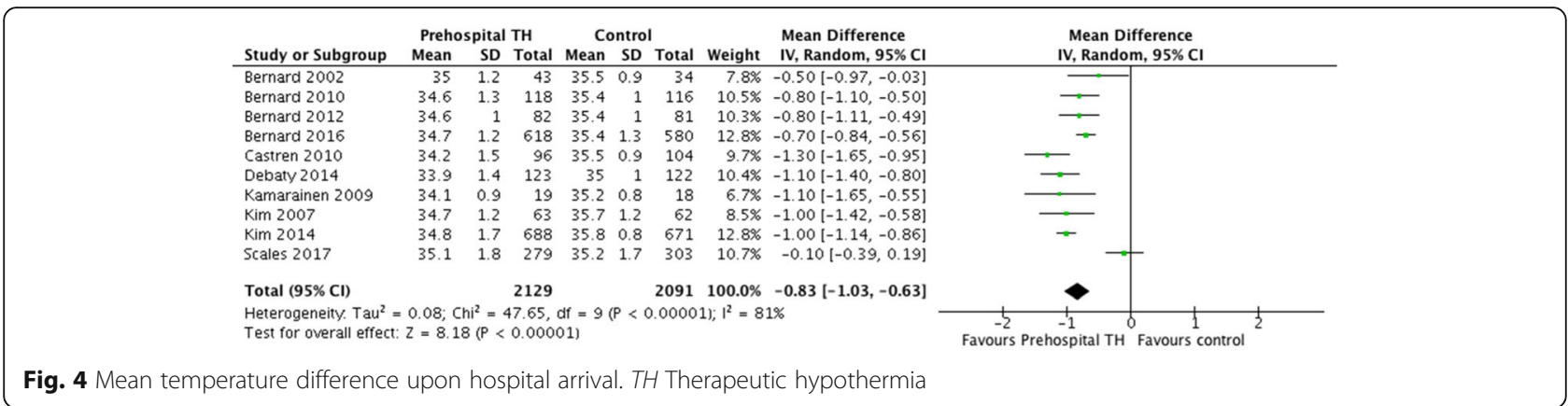

good neurological outcome. A limitation of included studies relates to the inconsistent definition of good neurological outcome, however. For example, researchers in one trial reported only rates of broadly defined 'severe neurological deficits' [20]. In three of the included studies, investigators reported rates of discharge to home or to a rehabilitation facility as a surrogate for good neurological outcome $[11,17,18]$; yet, it was unclear whether any of the patients were discharged to home with only palliative care services. Researchers in one study reported good neurological outcome as the absence of neurological deficit. The remaining studies used an objective measure of neurological outcome with the CPC and modified Rankin Scale scores or full neurological recovery, which allows for more consistent comparisons [12, 19, 21-23].

Similar to earlier studies, our review suggests that prehospital TH may increase the rate of re-arrest $[10,26]$. This result was strongly influenced by one trial in which the re-arrest rate was significantly higher than in the control group [19]. The authors of that study postulated that rapid fluid infusion resulted in volume overload, which in the context of resuscitation may have led to higher re-arrest rates. However, we observed substantial heterogeneity across studies for this finding, and the higher re-arrest rate did not result in different rates of survival to hospital admission. It has been suggested that very early cooling-during the arrest or immediately following $\mathrm{ROSC}$-may also increase re-arrest risk, but our subgroup analysis did not support this hypothesis. There were no differences between groups in rates of pulmonary oedema, but this outcome was characterized by marked heterogeneity, and none of the studies documented explicit criteria for systematic screening for pulmonary oedema.

Our review is limited by methodological heterogeneity across all of the included papers. Although the majority of studies in this review were focused on measuring the same primary and secondary outcomes, there were a variety of differences in the protocols followed once patients were admitted to hospital, with in-hospital cooling typically left to the discretion of the unblinded treating physician. In-hospital cooling methods ranged from ice-cold intravenous fluids to surface cooling to not being cooled at all. Other sources of treatment heterogeneity arise from ongoing debate surrounding the optimal temperature target and duration of cooling, as well as practice pattern variability for timing of withdrawal of life-sustaining therapy, all of which could impact outcomes [3, 27, 28]. Further research should be done to investigate the effect of pre-hospital $\mathrm{TH}$ in the setting of a more standardized approach to in-hospital post-resuscitation care. Other limitations of studies included in our review include a lack of blinding of care providers, which may have introduced bias if other treatments were altered as a result of knowledge of treatment allocation, and possible selection bias.

\section{Conclusions}

Our review demonstrates that pre-hospital $\mathrm{TH}$ after OHCA effectively decreases body temperature at time of hospital arrival, but it does not improve rates of survival

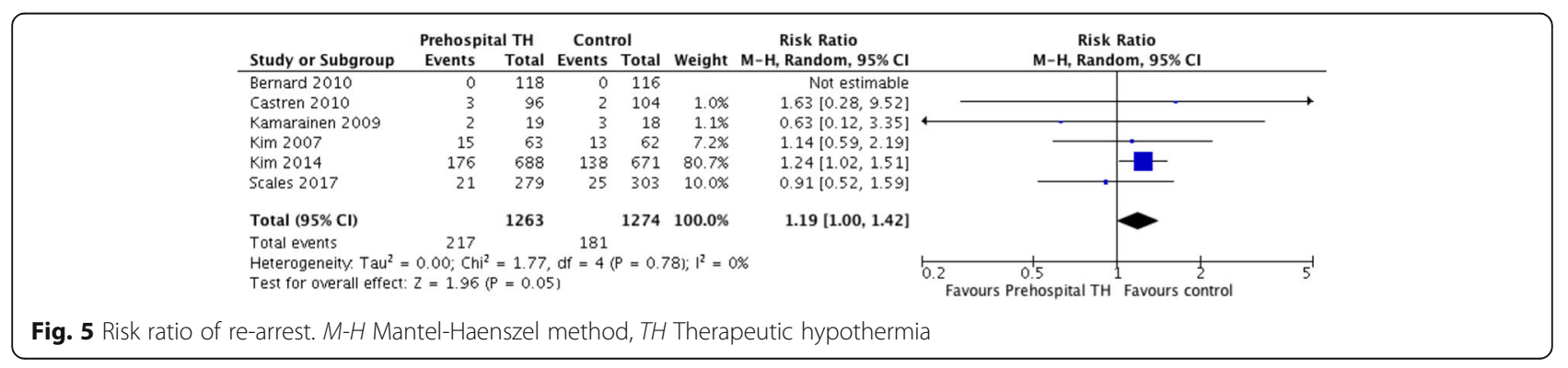


with good neurological outcome or overall survival. Furthermore, this study illustrates that there may be increased risk of adverse outcomes, with rates of rearrest higher in pre-hospital $\mathrm{TH}$.

\section{Additional files}

Additional file 1: Figure S1. Risk-of-bias graph: Review authors' judgements about each risk-of-bias item. Figure S2. Risk-of-bias summary: review authors' judgements about each risk of bias for each included study. Figure S3. Risk ratio of favourable neurological outcome sensitivity analysis. Figure S4. Risk ratio of survival to discharge with a shockable VF rhythm. Figure S5. Risk ratio of survival to discharge with a non-shockable rhythm. Figure S6. Sensitivity analysis of temperature upon hospital admission with Scales et al. [12] study removed. Figure S7. Risk ratio of pulmonary oedema. Figure S8. Risk ratio of survival at hospital arrival. Figure S9. Subgroup analysis for timing of cooling and survival to discharge. Figure S10. Subgroup analysis for timing of cooling and re-arrest. (DOCX 9669 kb)

\section{Abbreviations}

C: Comparator; CPC: Cerebral Performance Categories Scale; I: Intervention; MD: Mean difference; M-H: Mantel-Haenszel method; mRS: Modified Rankin Scale; OHCA: Out-of-hospital cardiac arrest; PEA: Pulseless electrical activity; PRISMA: Preferred Reporting Items for Systematic Reviews and Meta-Analyses statement; RCT: Randomised controlled trial; ROSC: Return of spontaneous circulation; RR: Risk ratio; TH: Therapeutic hypothermia; TTM: Targeted temperature management; VF: Ventricular fibrillation; VT: Ventricular tachycardia

\section{Acknowledgements}

Not applicable.

\section{Funding}

DCS received an operating grant from the Canadian Institutes of Health.

\section{Availability of data and materials}

Not applicable.

\section{Authors' contributions}

PJL, DB and DCS conceived of the study. PJL, DB and DCS designed the study. PJL, DB and DCS implemented the study and collected data. PJL and DB developed the analytical plan and statistical analyses. PJL, DB and DCS drafted the manuscript. All authors read and approved the final manuscript.

\section{Ethics approval and consent to participate}

Not applicable.

\section{Consent for publication}

Not applicable.

\section{Competing interests}

The authors declare that they have no competing interests.

\section{Publisher's Note}

Springer Nature remains neutral with regard to jurisdictional claims in published maps and institutional affiliations.

\section{Author details}

'Department of Internal Medicine, University of Toronto, Toronto, ON, Canada. ${ }^{2}$ Department of Critical Care Medicine, Sunnybrook Health Sciences Centre, Toronto, ON, Canada. Interdepartmental Division of Critical Care Medicine, University of Toronto, Toronto, ON, Canada.
Received: 28 November 2017 Accepted: 8 February 2018

Published online: 13 March 2018

\section{References}

1. Hypothermia after Cardiac Arrest Study Group. Mild therapeutic hypothermia to improve the neurologic outcome after cardiac arrest. N Engl J Med. 2002;346:549-56.

2. Arrich J, Holzer M, Havel C, Müllner M, Herkner H. Hypothermia for neuroprotection in adults after cardiopulmonary resuscitation. Cochrane Database Syst Rev. 2016;2:CD004128.

3. Nielsen N, Wetterslev J, Cronberg T, Erlinge D, Gasche Y, Hassager C, Horn J, Hovdenes J, Kjaergaard J, Kuiper M, et al. Targeted temperature management at $33^{\circ} \mathrm{C}$ versus $36^{\circ} \mathrm{C}$ after cardiac arrest. N Engl J Med. 2013;369:2197-206.

4. Howes D, Gray SH, Brooks SC, Boyd JG, Djogovic D, Golan E, Green RS, Jacka MJ, Sinuff T, Chaplin T, et al. Canadian guidelines for the use of targeted temperature management (therapeutic hypothermia) after cardiac arrest: a joint statement from the Canadian Critical Care Society (CCCS), Canadian Neurocritical Care Society (CNCCS), and the Canadian Critical Care Trials Group (CCCTG). Resuscitation. 2016;98:48-63.

5. Nikolaou NI, Arntz HR, Bellou A, Beygui F, Bossaert LL, Cariou A, Initial management of acute coronary syndromes section Collaborator. European Resuscitation Council Guidelines for Resuscitation 2015 Section 8. Initial management of acute coronary syndromes. Resuscitation. 2015;95:264-77.

6. Bernard SA, Gray TW, Buist MD, Jones BM, Silvester W, Gutteridge G, Smith K. Treatment of comatose survivors of out-of-hospital cardiac arrest with induced hypothermia. N Engl J Med. 2002;346:557-63.

7. Haugk M, Testori C, Sterz F, Uranitsch M, Holzer M, Behringer W, Herkner H, Time to Target Temperature Study Group. Relationship between time to target temperature and outcome in patients treated with therapeutic hypothermia after cardiac arrest. Crit Care. 2011;15:R101.

8. Lee BK, Jeung KW, Jung YH, Lee DH, Lee SM, Cho YS, Heo T, Yun JG, Min YI. Relationship between timing of cooling and outcomes in adult comatose cardiac arrest patients treated with targeted temperature management. Resuscitation. 2017;113:135-41.

9. Arrich J, Holzer M, Havel C, Warenits AM, Herkner H. Pre-hospital versus inhospital initiation of cooling for survival and neuroprotection after out-ofhospital cardiac arrest. Cochrane Database Syst Rev. 2016;3:CD010570.

10. Huang FY, Huang BT, Wang PJ, Zuo ZL, Heng Y, Xia TL, Gui YY, Lv WY, Zhang C, Liao YB, et al. The efficacy and safety of prehospital therapeutic hypothermia in patients with out-of-hospital cardiac arrest: a systematic review and meta-analysis. Resuscitation. 2015;96:170-9.

11. Bernard SA, Smith K, Finn J, Hein C, Grantham H, Bray JE, Deasy C, Stephenson M, Williams TA, Straney LD, et al. Induction of therapeutic hypothermia during out-of-hospital cardiac arrest using a rapid infusion of cold saline: the RINSE Trial (Rapid Infusion of Cold Normal Saline). Circulation. 2016;134:797-805.

12. Scales DC, Cheskes S, Verbeek PR, Pinto R, Austin D, Brooks SC, Dainty KN, Goncharenko K, Mamdani M, Thorpe KE, et al. Prehospital cooling to improve successful targeted temperature management after cardiac arrest: a randomized controlled trial. Resuscitation. 2017;121:187-94.

13. JPT H, Green S, editors. Cochrane handbook for systematic reviews of interventions. Version 5.1.0 [updated Mar 201 1]. London: The Cochrane Collaboration. http://handbook.cochrane.org

14. van Swieten JC, Koudstaal PJ, Visser MC, Schouten HJ, van Gijn J. Interobserver agreement for the assessment of handicap in stroke patients. Stroke. 1988;19:604-7.

15. Brain Resuscitation Clinical Trial I Study Group. A randomized clinical study of cardiopulmonary-cerebral resuscitation: design, methods, and patient characteristics. Am J Emerg Med. 1986;4:72-86.

16. Review Manager (RevMan) [computer program]. Version 5.3. Copenhagen: The Nordic Cochrane Centre, The Cochrane Collaboration; 2014.

17. Bernard SA, Smith K, Cameron P, Masci K, Taylor DM, Cooper DJ, Kelly AM, Silvester W, Rapid Infusion of Cold Hartmanns (RICH) Investigators. Induction of therapeutic hypothermia by paramedics after resuscitation from out-ofhospital ventricular fibrillation cardiac arrest: a randomized controlled trial. Circulation. 2010;122:737-42.

18. Bernard SA, Smith K, Cameron P, Masci K, Taylor DM, Cooper DJ, Kelly AM, Silvester W, Rapid Infusion of Cold Hartmanns Investigators. Induction of prehospital therapeutic hypothermia after resuscitation from nonventricular fibrillation cardiac arrest. Crit Care Med. 2012;40:747-53. 
19. Kim F, Nichol G, Maynard C, Hallstrom A, Kudenchuk PJ, Rea T, Copass MK, Carlbom D, Deem S, Longstreth WT Jr, et al. Effect of prehospital induction of mild hypothermia on survival and neurological status among adults with cardiac arrest: a randomized clinical trial. JAMA. 2014;311:45-52

20. Kim F, Olsufka M, Longstreth WT Jr, Maynard C, Carlbom D, Deem S, Kudenchuk P, Copass MK, Cobb LA. Pilot randomized clinical trial of prehospital induction of mild hypothermia in out-of-hospital cardiac arrest patients with a rapid infusion of $4^{\circ} \mathrm{C}$ normal saline. Circulation. 2007;115:3064-70.

21. Kamarainen A, Virkkunen I, Tenhunen J, Yli-Hankala A, Silfvast T. Prehospital therapeutic hypothermia for comatose survivors of cardiac arrest: a randomized controlled trial. Acta Anaesthesiol Scand. 2009;53:900-7.

22. Debaty G, Maignan M, Savary D, Koch FX, Ruckly S, Durand M, Picard J, Escallier C, Chouquer R, Santre C, et al. Impact of intra-arrest therapeutic hypothermia in outcomes of prehospital cardiac arrest: a randomized controlled trial. Intensive Care Med. 2014;40:1832-42.

23. Castren M, Nordberg P, Svensson L, Taccone F, Vincent JL, Desruelles $D$, Eichwede F, Mols P, Schwab T, Vergnion M, et al. Intra-arrest transnasal evaporative cooling: a randomized, prehospital, multicenter study (PRINCE: Pre-ROSC IntraNasal Cooling Effectiveness). Circulation. 2010;122:729-36.

24. Diao M, Huang F, Guan J, Zhang Z, Xiao Y, Shan Y, Lin Z, Ding L. Prehospital therapeutic hypothermia after cardiac arrest: a systematic review and metaanalysis of randomized controlled trials. Resuscitation. 2013;84:1021-8.

25. Hunter BR, O'Donnell DP, Allgood KL, Seupaul RA. No benefit to prehospital initiation of therapeutic hypothermia in out-of-hospital cardiac arrest: a systematic review and meta-analysis. Acad Emerg Med. 2014;21:355-64.

26. Nie C, Dong J, Zhang P, Liu X, Han F. Prehospital therapeutic hypothermia after out-of-hospital cardiac arrest: a systematic review and meta-analysis. Am J Emerg Med. 2016;34:2209-16.

27. Elmer J, Torres C, Aufderheide TP, Austin MA, Callaway CW, Golan E, Herren H, Jasti J, Kudenchuk PJ, Scales DC, et al. Association of early withdrawal of life-sustaining therapy for perceived neurological prognosis with mortality after cardiac arrest. Resuscitation. 2016:102:127-35.

28. Scales DC, Golan E, Pinto R, Brooks SC, Chapman M, Dale CM, Jichici D, Rubenfeld GD, Morrison $\sqcup$, Strategies for Post-Arrest Resuscitation Care Network. Improving appropriate neurologic prognostication after cardiac arrest: a stepped wedge cluster randomized controlled trial. Am J Respir Crit Care Med. 2016;194:1083-91.

\section{Submit your next manuscript to BioMed Central and we will help you at every step:}

- We accept pre-submission inquiries

- Our selector tool helps you to find the most relevant journal

- We provide round the clock customer support

- Convenient online submission

- Thorough peer review

- Inclusion in PubMed and all major indexing services

- Maximum visibility for your research

Submit your manuscript at wuw biomedcentral.com/submit

) Biomed Central 